\title{
The Phox2 pathway is differentially expressed in neuroblastoma tumors, but no mutations were found in the candidate tumor suppressor gene $\mathrm{PHOX} 2 \mathrm{~A}$
}

\author{
ANNICA WILZÉN ${ }^{1}$, STAFFAN NILSSON ${ }^{2}$, ROSE-MARIE SJÖBERG ${ }^{1}$, \\ PER KOGNER $^{3}$, TOMMY MARTINSSON ${ }^{1}$ and FRIDA ABEL ${ }^{1,2}$ \\ ${ }^{1}$ Department of Clinical Genetics, Gothenburg University, S-416 85 Gothenburg; ${ }^{2}$ Department of Mathematical \\ Statistics, Chalmers University of Technology, S-412 96 Gothenburg; ${ }^{3}$ Childhood Cancer Research Unit, \\ Karolinska Institutet, Astrid Lindgren Children's Hospital Q6:05, S-171 76 Stockholm, Sweden
}

Received September 4, 2008; Accepted October 22, 2008

DOI: 10.3892/ijo_00000196

\begin{abstract}
Neuroblastoma (NB), a tumor of the sympathetic nervous system, is the most common solid tumor in childhood. By microarray expression analysis (Affymetrix HU133A) important players in the noradrenalin biosynthesis pathway (DBH, DDC, GATA2, GATA3, PHOX2A, PHOX2B, SLC6A2 $S L C 18 A 1$ and $T H$ ) were found to be among the top ranked genes in showing lower expression in unfavorable NB tumor types as compared to favorable ones. By quantitative PCR with TaqMan, this result was significantly verified for all transcripts $(\mathrm{p}<0.05$, one-tailed) in a new set of 11 primary NB tumors (5 favorable vs. 6 unfavorable). PHOX2A, a downstream target of Phox $2 \mathrm{~b}$, was found to be the sixth ranked gene from the microarray gene list. Since the PHOX2A gene is localized in a tumor suppressor candidate region at $11 \mathrm{q}$, we screened this gene for mutations by DNA sequencing in 47 tumors of different stages. However, no critical changes were found that could support its role in tumor development or progression. Overall, the findings in this study either suggest that expression of this pathway could be a predictive differentiation marker of NB tumors, or our results could also imply that the noradrenalin biosynthesis pathway is involved in tumor pathogenesis.
\end{abstract}

\section{Introduction}

Neuroblastoma (NB) develops from the primitive sympathetic neuronal precursors and the tumor cells probably develop during the embryonic period. Most NB's are undifferentiated tumors and consist of immature neuroblasts. Tumors showing partial differentiation are named ganglioneuroblastoma and

Correspondence to: Dr Frida Abel, Chalmers University of Technology, Institution of Mathematical Sciences, Department of Mathematical Statistics, S-412 96 Gothenburg, Sweden

E-mail: frida.abel@gu.se

Key words: noradrenergic, child, vesicular monoamine transporter 1 the most differentiated state is ganglioneuroma. NB arise in the adrenal medulla $(\sim 50 \%)$, or elsewhere along the sympathetic ganglia in the chest, abdomen or in pelvis (1). Anatomic pathophysiology of NB is closely connected to the development of the sympathetic nervous system in infants, where the origin and migration of the neuroblasts during embryogenesis correlates to the sites of the primary tumors. The localization of the tumors seems to vary with age of onset, small children, i.e. those who are diagnosed before one year, frequently have tumors in thorax and pelvis, while older children develop tumors mainly in abdominal cavity.

NB shows a wide spectrum of biological behavior and there are various genetic features observed in the tumors. The most important showing a prognostic value are $M Y C N$ amplification and 1p-deletion $(1,2)$. Other chromosomal abnormalities frequently observed in NB tumors are deletions of chromosomes 11q, 14q and 3p, and gain of 17q. Recent findings show that the prevalence of $11 \mathrm{q}$ deletions is similar to $1 \mathrm{p}$ deletions and associated with stage 4 disease (3). Guo and colleagues found 11q deletions at a frequency of $43 \%$ of tumor cases, which suggest it to be the most common deletion observed in NB tumors (4). Moreover, the 11q status has also been shown to enable the identification of patients with an increased risk for relapses (3). Deletion-mapping studies have defined a crucial region at 11q23.3-q24. However, this region was initially defined by only a few tumor specimens and most cases show large hemizygous deletions from 11q14 to 11qter (4-6). The different heterozygously deleted chromosomal regions in NB tumors (e.g. 1p, 11q, 3p) have long been suggested to harbour one or several tumor suppressor genes with mutations in the remaining allele. Several tumor suppressor candidates have been proposed during the years, but so far the $P H O X 2 B$ gene located at $4 \mathrm{p} 13$ is the most trustworthy candidate with identified mutations, which are believed to play a role in NB pathogenesis (7-10). Phox $2 b$ is a homeobox transcription factor of the noradrenergic biosynthesis pathway, which controls parts of the neural developmental program as well as maintenance of noradrenergic cells $(11,12)$. Phox $2 b$ is essential to induce expression of its homologue Phox $2 \mathrm{a}$ $(13,14)$, which is localized near the deletion breakpoint of several 11q-deleted NB tumor specimens (i.e. 11q13.4). 
Phox $2 \mathrm{a}$ and Phox $2 \mathrm{~b}$ are coexpressed in adult noradrenergic cells, and they are able to induce transcription of each other $(12,15)$ and to auto-regulate their own expression (16). Together, these two highly conserved proteins control expression of downstream targets important for the noradrenergic phenotype.

In the current study, we performed a global microarray expression analysis (Affymetrix HU133A) on six primary NB tumors from a Swedish patient group. From the microarray top-ranked genes, nine transcripts belonging to the noradrenergic biosynthesis pathway were selected for further verification by real-time PCR in an expanded tumor set $(\mathrm{n}=18)$. The 6th ranked gene was the paired-homeobox $2 \mathrm{a}$ gene $(P H O X 2 A)$. Due to its near connection to Phox $2 b$ and its location on $11 \mathrm{q}$, we screened $P H O X 2 A$ for inactivating mutations to investigate its potential role as a tumor suppressor in NB.

\section{Materials and methods}

Experimental design. Tumors were divided into two biologically based groups by the following criteria: favorable (F); NB patient with no evidence of disease (NED) with a primary tumor staged 1-3 with no $M Y C N$-amplification (MNA), no 1p deletion (1pdel), and no 11q deletion (11qdel). Unfavorable (UF); NB patient with advanced stage of disease or dead of disease (DOD) with a primary tumor staged 4 , or with a primary tumor staged 3 with $M Y C N$-amplification and/or 1pdel and/or 11qdel (Table I).

Patients. A set of 56 primary NB tumors of different stages and one Wilms tumor was used in the study, six tumors were used for the microarray study and 18 tumors were used for the quantitative PCR (QPCR) expression analysis, of which five were included in both the microarray and QPCR expression analysis (Table I). A set of 47 tumors were included for DNA sequencing, of which eight samples were used in both QPCR expression and sequencing analysis and one sample was used in both microarray and sequencing analyses. The NB cell line SK-N-AS was employed as a calibrator control for the expression analysis. Tumor samples were obtained freshfrozen at surgery from Swedish patients with diagnosed NB. The patients were staged according to the International Neuroblastoma Staging System criteria (17). MNA and 1pdel status of the tumor samples have been investigated in previous studies $(18,19)$ using FISH analysis and PCR-based DNA polymorphism. Moreover, copy number variations of MNA, 1 pdel and 11qdel have also been investigated by Affymetrix 250K SNP arrays (20).

RNA preparation and microarray analysis. Snap-frozen tumor material $(30 \mathrm{mg}$ ) from 19 samples were homogenized by TissueLyser (Qiagen, Hilden, Germany) and total RNA was extracted using Totally RNA (Ambion, St. Austin, TX), according to the suppliers' protocols. The total RNA purity and integrity were evaluated by spectrophotometric analysis using the ND-1000 (Saveen Werner AB, Malmö, Sweden) and the Bioanalyzer 2100 (Agilent, Palo Alto, CA), respectively. All RNA samples showed an $\mathrm{A}_{260} / \mathrm{A}_{280} \mathrm{~nm}$ ratio in the range of 1.9-2.1, and RNA Integrity Numbers $(\mathrm{RIN})>7.0$. A global expression analysis was performed on six tumor samples; three favorable (14E6, 12E8 and 15E3) and three unfavorable (10R2, 15R3 and 16R4) NB tumors (Table I). The total RNA was labeled and hybridized to the Affymetrix oligo array U133A at the Swegene Microarray Resource Centre (MARC) in Lund. Swegene MARC provided expression raw data and expression evaluation. Normalization, clustering analysis and statistical analysis of expression data was done in collaboration with the Bioinformatics Core Facility in Gothenburg. Raw microarray data were processed, visualized and quality controlled using packages from Bioconductor. For all probe sets on the microarray, a two-side SE-corrected t-test on the set of six patients was performed to identify candidate genes with a significant differential expression pattern between NB patients with unfavorable vs. favorable outcome.

QPCR with TaqMan. Eighteen NB tumors, of which nine were classified as favorable and nine as unfavorable were used for real-time PCR expression analysis with TaqMan microfluid cards (MFC; Table I). The RNA samples were reverse transcribed using High-Capacity cDNA reverse transcription kit (Applied Biosystems, Foster City, USA). cDNA synthesis was performed in $20 \mu \mathrm{l}$ reactions containing $1 \mu \mathrm{g}$ RNA; $1 \mathrm{X}$ RT buffer; 4 mM dNTP mix; 1X RT random primers; $50 \mathrm{U}$ reverse transcriptase and $20 \mathrm{U}$ RNase inhibitor. Samples were reverse transcribed under following conditions: $25^{\circ} \mathrm{C}$ for $10 \mathrm{~min}, 37^{\circ} \mathrm{C}$ for $120 \mathrm{~min}$ and $85^{\circ} \mathrm{C}$ for $5 \mathrm{sec}$.

Inventoried TaqMan assays for nine genes in the Phox2 pathway, six endogenous controls and 82 other genes of interest were selected, and added to the MFC's chart. Cards holding 96 preloaded assays were ordered from Applied Biosystems. Real-time PCR was prepared by filling each reservoir with a mixture (in total $100 \mu \mathrm{l}$ ) containing $1 \mathrm{X}$ TaqMan mastermix and $83 \mathrm{ng}$ total RNA converted to cDNA. The 384-well cards were processed and run according to manufacturer's protocol using the ABI PRISM ${ }^{\circledR} 7900$ HT Sequence Detection System (SDS v.2.2, Applied Biosystems). Amplification reactions were run in simplex. Thermal cycling was initiated with a 2 min incubation at $50^{\circ} \mathrm{C}$, followed by a denaturation step of $10 \mathrm{~min}$ at $94.5^{\circ} \mathrm{C}$ and then by 40 cycles of $30 \mathrm{sec}$ at $97^{\circ} \mathrm{C}$ and $1 \mathrm{~min}$ at $59.7^{\circ} \mathrm{C}$.

QPCR - Quantification and normalization. Quantification was performed by the relative quantification method $(\Delta \Delta \mathrm{Ct}$ method). In summary, threshold and baseline were set manually in SDS and Ct values were extracted. All samples were normalized to the geometric mean of three endogenous genes: $A D A, G A P D H, G U S B$. To adjust for discrepancy between runs, all samples were compared to a calibrator sample (SK-N-AS), which was loaded on each card. Fold changes and statistical comparison between groups (UF vs. F) was calculated using $\log _{2}(\mathrm{Ct})$ expression values from each sample. The significance of differential expression was calculated using a one-tailed t-test. The correlation of expression between transcripts in the Phox2-pathway was calculated by Pearson's correlation test within each group. The relation of expression values detected by microarray analysis vs. QPCR analysis was also calculated by Pearson's correlation. In order to quality check the data, box plots for each gene was plotted using $\log _{2}$ expression values and they was exploited 
Table I. Clinical data of tumors used in this study.

\begin{tabular}{|c|c|c|c|c|c|c|c|c|c|}
\hline No. & Case & Stage & Age & Outcome & NMA & 1pdel & 11qdel & Analysis & $\begin{array}{c}\text { Group in } \\
\text { expression analysis }\end{array}$ \\
\hline 1 & $18 \mathrm{E} 8$ & 1 & 9 & NED & $\mathrm{Neg}$ & Neg & Neg & $Q P C R$ & $\mathrm{~F}$ \\
\hline 2 & $14 \mathrm{E} 6$ & 1 & 13 & NED & $\mathrm{Neg}$ & Neg & $\mathrm{Neg}$ & MA, PHOX2A seq & $\mathrm{F}$ \\
\hline 3 & $35 \mathrm{R} 5$ & 1 & 14 & NED & $\mathrm{Neg}$ & Neg & $\mathrm{Na}$ & PHOX2A seq & \\
\hline 4 & $35 \mathrm{R} 8$ & 1 & 14 & NED & $\mathrm{Neg}$ & $\mathrm{Neg}$ & Neg & $Q P C R$ & $\mathrm{~F}$ \\
\hline 5 & $16 \mathrm{E} 1$ & 1 & 18 & NED & $\mathrm{Neg}$ & $\mathrm{Neg}$ & $\mathrm{Neg}$ & PHOX2A seq & \\
\hline 6 & $15 \mathrm{E} 6$ & 1 & 22 & NED & $\mathrm{Neg}$ & $\mathrm{Neg}$ & $\mathrm{Na}$ & PHOX2A seq & \\
\hline 7 & $14 \mathrm{R} 4$ & 1 & 32 & NED & $\mathrm{Neg}$ & Neg & $\mathrm{Neg}$ & PHOX2A seq & \\
\hline 8 & $31 \mathrm{R} 8$ & 1 & 45 & NED & Neg & Neg & Neg & $Q P C R$ & $\mathrm{~F}$ \\
\hline 9 & 20R9 & 2 & 3 & NED & $\mathrm{Na}$ & $\mathrm{Na}$ & $\mathrm{Na}$ & $Q P C R$ & $\mathrm{~F}$ \\
\hline 10 & $33 \mathrm{R} 7$ & 2 & 3 & NED & Neg & Neg & $\mathrm{Na}$ & $Q P C R$ & $\mathrm{~F}$ \\
\hline 11 & $25 \mathrm{R} 8$ & 2 & 6 & NED & $\mathrm{Neg}$ & $\mathrm{Neg}$ & $\mathrm{Neg}$ & PHOX2A seq & \\
\hline 12 & $23 \mathrm{R} 4$ & 2 & 9 & NED & Neg & $\mathrm{Neg}$ & neg & $Q P C R, P H O X 2 A$ seq & $\mathrm{F}$ \\
\hline 13 & $35 \mathrm{R} 2$ & 2 & 48 & NED & Neg & Neg & Neg & PHOX2A seq & \\
\hline 14 & $10 \mathrm{E} 4$ & 2 & 2 & DOD & Neg & Neg & Neg & PHOX2A seq & \\
\hline 15 & $12 \mathrm{E} 1$ & 2 & 76 & DOD & Pos & Neg & Pos & PHOX2A seq & \\
\hline 16 & $25 \mathrm{R} 0$ & 3 & 1 & NED & Neg & Neg & $\mathrm{Na}$ & $Q P C R$ & $\mathrm{~F}$ \\
\hline 17 & $12 \mathrm{R} 4$ & 3 & 2 & NED & Neg & Pos & Neg & PHOX2A seq & \\
\hline 18 & $34 \mathrm{R} 1$ & 3 & 6 & NED & $\mathrm{Neg}$ & $\mathrm{Neg}$ & $\mathrm{Na}$ & PHOX2A seq & \\
\hline 19 & $12 \mathrm{E} 8$ & 3 & 7 & NED & Neg & Neg & $\mathrm{Neg}$ & $M A, Q P C R$ & $\mathrm{~F}$ \\
\hline 20 & $15 \mathrm{R} 8$ & 3 & 9 & NED & Neg & (Pos) & $\mathrm{Na}$ & PHOX2A seq & \\
\hline 21 & $15 \mathrm{E} 3$ & 3 & 12 & NED & Gain & UB & Neg & $M A, Q P C R, P H O X 2 A$ seq & $\mathrm{F}$ \\
\hline 22 & $23 \mathrm{R} 2$ & 3 & 29 & NED & Pos & Pos & $\mathrm{Na}$ & PHOX2A seq & \\
\hline 23 & $16 \mathrm{R} 4$ & 3 & 30 & NED & Pos & Neg & Neg & $M A, Q P C R, P H O X 2 A$ seq & UF \\
\hline 24 & $23 \mathrm{R} 0$ & 3 & 43 & NED & Neg & Neg & $\mathrm{Na}$ & PHOX2A seq & \\
\hline 25 & 19R6 & 3 & 8 & DOD & Pos & Pos & $\mathrm{Neg}$ & $Q P C R, P H O X 2 A$ seq & UF \\
\hline 26 & 9R9 & 3 & 24 & DOD & Neg & Pos & Pos & $Q P C R, P H O X 2 A$ seq & UF \\
\hline 27 & $13 \mathrm{R} 1$ & 3 & 37 & DOD & Pos & Pos & Neg & PHOX2A seq & \\
\hline 28 & $13 \mathrm{E} 6$ & 3 & 48 & DOD & Pos & Pos & Pos & PHOX2A seq & \\
\hline 29 & $10 \mathrm{R} 8$ & 3 & 83 & DOD & Neg & (Pos) & Pos & PHOX2A seq & \\
\hline 30 & $10 \mathrm{E} 6$ & 4 & 11 & NED & Pos & Pos & Neg & PHOX2A seq & \\
\hline 31 & 29R2 & 4 & 15 & NED & Pos & Pos & $\mathrm{Na}$ & $Q P C R$ & UF \\
\hline 32 & $26 \mathrm{R} 0$ & 4 & 36 & NED & Pos & UB & Pos & PHOX2A seq & \\
\hline 33 & $17 \mathrm{R} 3$ & 4 & 44 & NED & Neg & Neg & $\mathrm{Na}$ & PHOX2A seq & \\
\hline 34 & $16 \mathrm{E} 3$ & 4 & 10 & DOD & Pos & Pos & Neg & PHOX2A seq & \\
\hline 35 & $36 \mathrm{R} 3$ & 4 & 10 & DOD & Neg & UB & Neg & PHOX2A seq & \\
\hline 36 & $10 \mathrm{R} 2$ & 4 & 15 & DOD & $\mathrm{Na}$ & (Pos) & Neg & $M A, Q P C R, P H O X 2 A$ seq & UF \\
\hline 37 & $26 \mathrm{R} 8$ & 4 & 21 & DOD & Pos & Pos & $\mathrm{Na}$ & $Q P C R$ & UF \\
\hline 38 & $13 \mathrm{R} 0$ & 4 & 27 & DOD & Pos & Pos & Neg & QPCR, PHOX2A seq & UF \\
\hline 39 & $15 \mathrm{R} 3$ & 4 & 28 & DOD & $\mathrm{Neg}$ & (Pos) & $\mathrm{Na}$ & $M A, Q P C R$ & UF \\
\hline 40 & $11 \mathrm{R} 9$ & 4 & 37 & DOD & $\mathrm{Neg}$ & Neg & Pos & PHOX2A seq & \\
\hline 41 & $11 \mathrm{E} 2$ & 4 & 41 & DOD & Neg & Neg & Neg & PHOX2A seq & \\
\hline 42 & $12 \mathrm{R} 6$ & 4 & 50 & DOD & Pos & Pos & Neg & PHOX2A seq & \\
\hline 43 & $19 \mathrm{R} 0$ & 4 & 52 & DOD & $\mathrm{Neg}$ & (Pos) & $\mathrm{Na}$ & PHOX2A seq & \\
\hline 44 & $34 \mathrm{R} 9$ & 4 & 53 & DOD & $\mathrm{Neg}$ & Neg & Pos & PHOX2A seq & \\
\hline 45 & $3 \mathrm{E} 2$ & 4 & 58 & DOD & $\mathrm{Neg}$ & Neg & Pos & PHOX2A seq & \\
\hline 46 & $17 \mathrm{R} 2$ & 4 & 80 & DOD & Neg & Neg & $\mathrm{Na}$ & PHOX2A seq & \\
\hline 47 & $12 \mathrm{E} 6$ & 4 & 137 & DOD & Pos & Neg & $\mathrm{Na}$ & $Q P C R, P H O X 2 A$ seq & UF \\
\hline 48 & $25 \mathrm{R} 3$ & $4 \mathrm{M}$ & 10 & NED & Neg & Neg & Neg & PHOX2A seq & \\
\hline 49 & $16 \mathrm{E} 2$ & $4 \mathrm{~S}$ & 0 & NED & $\mathrm{Neg}$ & Neg & $\mathrm{Neg}$ & PHOX2A seq & \\
\hline
\end{tabular}


Table I. Continued.

\begin{tabular}{|c|c|c|c|c|c|c|c|c|c|}
\hline No. & Case & Stage & Age & Outcome & NMA & 1pdel & 11qdel & Analysis & $\begin{array}{c}\text { Group in } \\
\text { expression analysis }\end{array}$ \\
\hline 50 & $12 \mathrm{E} 5$ & $4 \mathrm{~S}$ & 1 & NED & $\mathrm{Neg}$ & Neg & $\mathrm{Neg}$ & PHOX2A seq & \\
\hline 51 & $13 \mathrm{E} 7$ & $4 \mathrm{~S}$ & 2 & NED & $\mathrm{Na}$ & $\mathrm{Na}$ & $\mathrm{Na}$ & PHOX2A seq & \\
\hline 52 & $13 \mathrm{R} 3$ & $4 \mathrm{~S}$ & 3 & NED & $\mathrm{Neg}$ & Neg & $\mathrm{Na}$ & PHOX2A seq & \\
\hline 53 & $10 \mathrm{R} 4$ & $4 \mathrm{~S}$ & 6 & NED & $\mathrm{Neg}$ & Neg & $\mathrm{Na}$ & PHOX2A seq & \\
\hline 54 & 21R6 & $4 \mathrm{~S}$ & 10 & NED & $\mathrm{Neg}$ & Neg & $\mathrm{Na}$ & PHOX2A seq & \\
\hline 55 & $12 \mathrm{R} 7$ & $4 \mathrm{~S}$ & 25 & NED & $\mathrm{Neg}$ & Neg & $\mathrm{Na}$ & PHOX2A seq & \\
\hline 56 & $11 \mathrm{E} 5$ & $4 \mathrm{~S}$ & 0 & DOD & $\mathrm{Neg}$ & Neg & $\mathrm{Neg}$ & PHOX2A seq & \\
\hline 57 & 19R3 & Wilms & 0 & $\mathrm{Na}$ & $\mathrm{Neg}$ & Pos & $\mathrm{Na}$ & PHOX2A seq & \\
\hline
\end{tabular}

Stage, clinical stage of NB; Wilms, Wilms tumor; Age, months at diagnosis; NED, no evidence of disease; DOD, dead of disease; Na, not available; 1p-del, 1p-deletion; Pos, positive; Neg, negative; UB, unbalanced; gain, $M Y C N<4$ times the ploidy; (Pos), Ambigous results; MA, micro array; QPCR, quanatitative PCR and PHOX2A seq, sequencing analysis of PHOX2A.

to identify outliers that could disturb the analysis and interpretation of the data.

DNA sequencing - sample preparation. DNA was enriched from 47 fresh-frozen tumor samples by the DNeasy kit from Qiagen (Table I). Throughout the PCR and sequencing steps, CEPH standard DNA (CEPH 1347-02, Applied Biosystems) was used as a positive control and water as a negative control.

DNA sequencing - primer design and PCR amplification. The genomic DNA sequence and the mRNA sequence (Accession number: NM_005169) of the PHOX2A gene were obtained from UCSC Genome Bioinformatics webpage (http://genome. ucsc.edu; Fig. 1). The primers, covering the promoter region (4 fragments) and exon 2, were designed using ExonPrimer (http://ihg.gsf.de/ihg/ExonPrimer.html), or PrimerExpress (Applied Biosystems). Primers covering exon 1 and exon 3 were adapted from Nakano et al (21). Primer sequences are available on request. The PCR reactions were set up using the automated workstation Biomek ${ }^{\circledR}$ FX (Beckman Coulter, www.beckmancoulter.com) in 384-well reaction plates. Touch Down-PCR (TD-PCR) was carried out in $10 \mu \mathrm{l}$ reactions containing 1X PCR buffer; $20 \mathrm{mM}$ dNTP mix, $0.25 \mathrm{U}$ Hot Star TaqPlus DNA polymerase (Qiagen), 5-10 $\mu \mathrm{M}$ primer (forward and reverse) and 25-50 ng genomic DNA. GC-rich fragments were run with 1X Q-solution (Qiagen) in the master mix. PCR amplifications for exon 1 and exon 3 were run according to Nakano et al (21) and thermal profiles for the other five fragments are available on request. TD-PCR products were cleansed using magnetic beads (AMPure, Agencourt, Bioscience Corporation, Beverly, MA) in the automated workstation Biomek NX (Beckman Coulter) and eluted in $\mathrm{dH}_{2} \mathrm{O}$.

DNA sequencing - sequence PCR and data analysis. Sequence PCR, using BigDye ${ }^{\circledR}$ Terminator v 3.1 Cycle Sequence kit (Applied Biosystems), was carried out in $10 \mu 1$ reactions containing $6 \mu 11: 3$ diluted template (TD-PCR product), 0.25-2 $\mu \mathrm{l}$ BDT, $1 \mathrm{X}$ BDT buffer; and 1.6 $\mu \mathrm{M}$ primer (forward or reverse) and run according to standard procedures. The

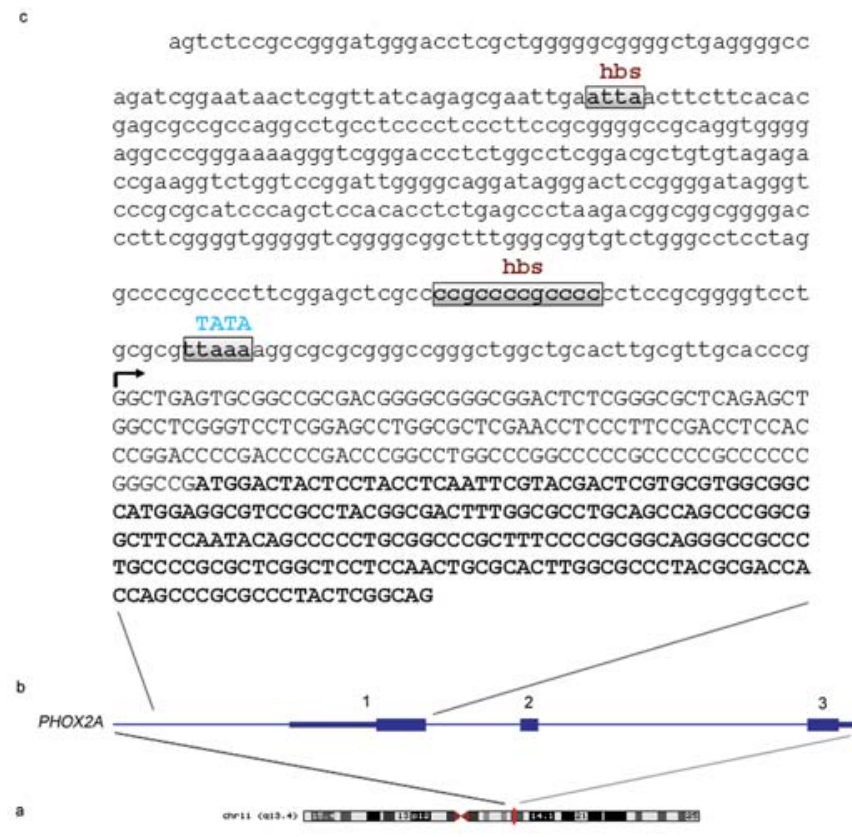

Figure 1. Schematic representation of the $P H O X 2 A$ gene. (a) $P H O X 2 A$ is located at chromosome band 11q13.4. (b) The gene contains three exons; exon 1 [389 base pairs (bp)], exon 2 (188 bp) and exon3 (1121 bp). (c) Regulatory sites in the promoter region of $P H O X 2 A$ are the Homeobox Binding Sites (hbs) marked in red, TATA-box (blue) and the transcription start site marked by an arrow. The translated sequence is shown in bold.

thermal profile for GC-rich fragments (exon 1 and 3) was modified to an initial denaturation step at $94^{\circ} \mathrm{C}$ for $3 \mathrm{~min}$, followed by 50 cycles of $96^{\circ} \mathrm{C}$ for $30 \mathrm{sec}, 50^{\circ} \mathrm{C}$ for $10 \mathrm{sec}$ and $60^{\circ} \mathrm{C}$ for $3 \mathrm{~min}$. Sequence-PCR was performed using the same primers as in the previous TD-PCR amplifications, except for two fragments (one in the promoter and one in exon 2) in which special sequencing primers were used. The sequencePCR products were cleansed using magnetic beads (CleanSeq, Agencourt) in the automated workstation Biomek NX (Beckman Coulter) and eluted in High Dye Formamide. The sequence reaction products were loaded on a 3730 DNA Analyzer (Applied Biosystems) and the results were analysed 
Table II. Transcripts analyzed by QPCR with TaqMan.

\begin{tabular}{|c|c|c|c|c|c|c|c|c|c|c|}
\hline \multirow[b]{3}{*}{ Gene } & \multirow[b]{3}{*}{ Description } & \multirow[b]{3}{*}{ Location } & \multirow[b]{3}{*}{$\begin{array}{c}\text { Accession } \\
\text { no. }\end{array}$} & \multirow[b]{3}{*}{$\begin{array}{c}\text { Assay } \\
\text { no. }\end{array}$} & \multicolumn{2}{|c|}{ Microarray } & \multicolumn{4}{|c|}{ QPCR } \\
\hline & & & & & \multirow[b]{2}{*}{ Rank } & \multirow[b]{2}{*}{$\begin{array}{l}\text { Fold } \\
\text { change }\end{array}$} & \multicolumn{2}{|c|}{$\operatorname{Ver}_{(6 \mathrm{~F}+6 \mathrm{UF})}$} & \multicolumn{2}{|c|}{ Total $_{(8 \mathrm{~F}+9 \mathrm{UF})}$} \\
\hline & & & & & & & $\begin{array}{c}\text { Fold } \\
\text { change }\end{array}$ & P-value & $\begin{array}{c}\text { Fold } \\
\text { change }\end{array}$ & P-value \\
\hline$D B H$ & GOI & $9 q 34$ & NM_000787 & Hs01089840_m1 & 18 & 10.8 & 15.0 & 0.004 & 11.8 & 0.0002 \\
\hline$D D C$ & GOI & $7 \mathrm{p} 11$ & NM_000790 & Hs00168031_m1 & 16 & 3.4 & 23.8 & 0.016 & 15.9 & 0.0024 \\
\hline GATA2 & GOI & $3 q 21.3$ & NM_032638 & Hs00231119_m1 & 19 & 8.1 & 4.2 & 0.026 & 6.0 & 0.0014 \\
\hline GATA3 & GOI & $10 \mathrm{p} 15$ & NM_001002295 & Hs00231122_m1 & 50 & 5.8 & 6.2 & 0.002 & 5.7 & 0.0004 \\
\hline PHOX $2 A$ & GOI & $11 q 13.4$ & NM_005169 & Hs00605931_mH & 6 & 4.2 & 26.3 & 0.022 & 11.0 & 0.0149 \\
\hline PHOX2B & GOI & $4 p 12$ & NM_003924 & Hs00243679_m1 & 178 & 3.9 & 17.6 & 0.004 & 8.5 & 0.0047 \\
\hline SLC18A1 & GOI & $8 p 21.3$ & NM_003053 & Hs00161839_m1 & 3 & 6.8 & 25.0 & 0.013 & 24.1 & 0.0010 \\
\hline SLC6A2 & GOI & $16 q 12.2$ & NM_001043 & Hs00426573_m1 & 7 & 4.1 & 540.3 & 0.001 & 201.1 & 0.0002 \\
\hline$T H$ & GOI & $11 \mathrm{p} 15.5$ & NM_199292 & Hs00165941_m1 & 31 & 4.9 & 10.6 & 0.013 & 7.6 & 0.0023 \\
\hline$G U S B$ & End. control & $7 q 11.21$ & NM_000181 & Hs99999908_m1 & & & & & & \\
\hline$A D A$ & End. control & $20 q 13.12$ & NM_000022 & Hs00163553_m1 & & & & & & \\
\hline$G A P D H$ & End. control & $12 \mathrm{p} 13.31$ & NM_002046 & Hs02786624_g1 & & & & & & \\
\hline
\end{tabular}

GOI, Gene of interest; End. control, endogenous control; location, chromosomal location; Assay no, TaqMan assay number according to Applied Biosystems (www@appliedbiosystems.com); rank, rank in gene-list sorted by statistical significance; Fold change, expression fold between biological groups (UF vs. F); P-value, one-tailed t-test assuming unequal variance; Ver (Verification), quantitative PCR results from the new tumor set (6 F vs. 6 UF) not used in the micro array study; total, quantitative PCR results from all tumor samples (8 F vs. 9 UF).

using the software programs Sequencing Analysis v. 5.2 and SeqScape v.2.5 (Applied Biosystems).

\section{Results}

Microarray analysis. The global microarray expression analysis (Affymetrix HU133A) containing 33,000 genes, was performed on three favorable and three unfavorable NB tumors. Genes showing lower expression in unfavorable compared to favorable tumors with a fold change over two were ranked according to statistical significance (Table II), resulting in a list of 1084 probe-sets. Out of the 50 top-ranked genes found to show lower expression in unfavorable tumors, eight genes belonged to the noradrenergic biosynthesis pathway. The 178th ranked transcript was the paired-like homeobox $2 \mathrm{~b}$ gene $(\mathrm{PHOX} 2 \mathrm{~B})$, which has been found to be mutated in a few hereditary and sporadic NB cases (7-10).

QPCR verification. Nine genes belonging to the noradrenergic biosynthesis pathway were selected for further verification by real-time RT-PCR; PHOX2A, PHOX2B, GATA2, GATA3, $D D C, D B H, S L C 6 A 2, S L C 18 A 1$ and $T H$. Six endogenous controls showing uniform expression on the microarray were also selected. Out of these, two transcripts (PEX7 and GK) showed expression values beneath the detection limit and they were therefore excluded from the analysis. In order to check for the stability of the remaining four endogenous controls, $\mathrm{M}$-values were calculated according to Vandesompele and colleagues (22). The control gene $18 \mathrm{~S}$ which showed the highest $\mathrm{M}$-value $(\mathrm{M}=2,59)$ was not uniformly expressed within the sample group and it was therefore excluded from the analysis (data not shown). Thus, the relative expression of the genes were quantified and normalized to the geometric mean of $A D A, G A P D H$ and GUSB. The distribution of expression values ( $\log _{2}$ values) for each transcript was visualized using box plots and identified case 25R0 (belonging to the favorable group) as an outlier for all transcripts (data not shown). This sample was therefore removed from the study, resulting in an analysis set of eight favorable versus nine unfavorable tumors $(n=17)$.

All nine transcripts showed significant lower expression $(p<0.05)$ in unfavorable vs. favorable NB tumors, both in the verification group and in the total analysis (Table II; Fig. 2). Gene expression values of all transcripts also correlated significantly within groups, except for GATA2 and GATA3 which only partially correlated to the others (data not shown). The correlation between microarray data and QPCR data was significant (Pearson's correlation $=0.6$; Fig. 3 ).

PHOX2A mutation analysis. From the microarray gene list the 6th ranked gene was found to be the paired-like homeobox 2a $(P H O X 2 A)$. A mutation screening of all coding regions as well as the regulatory sites of the $P H O X 2 A$ gene was performed by PCR-based sequencing analysis (Fig. 1). All sequence fragments of $P H O X 2 A$ were quality checked and aligned to the reference sequence (Accession number: NM_005169 and 365 bp promoter sequence derived from the UCSC genome browser). Sequences were run both in forward and reverse direction and covered $100 \%$ of the coding regions in $90 \%$ of the samples. The remaining $10 \%$ showed an $80-$ $99 \%$ coverage. In the promoter and the 5' UTR region there were coverage of $100 \%$ of the sequences in $83 \%$ of the samples 
DBH

GATA3

SLC18A1

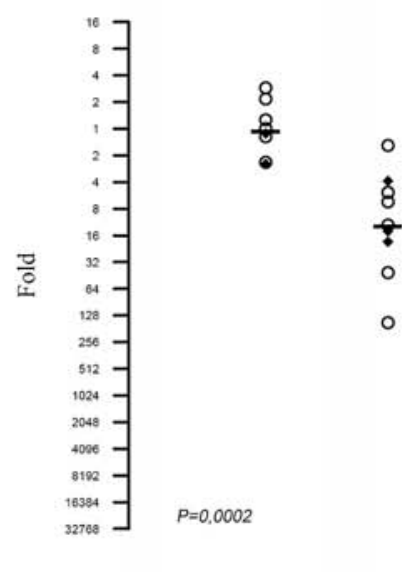

DDC
GATA2

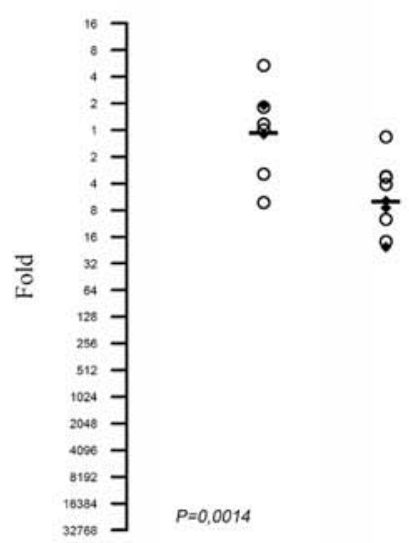

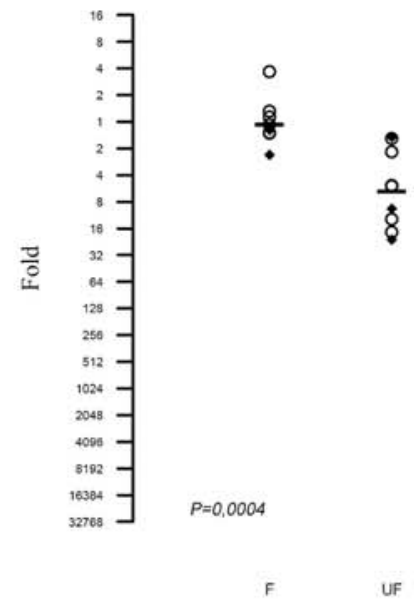

PHOX2A

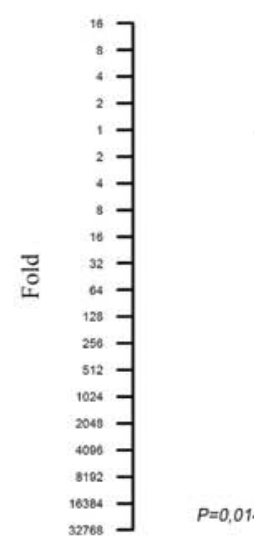

$\stackrel{8}{+}$

。

○

$P=0,0024$

$$
8
$$

$\overline{8}$

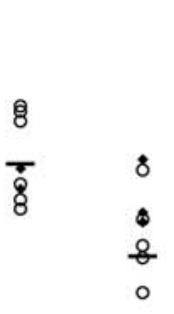

○

$P=0,0149$

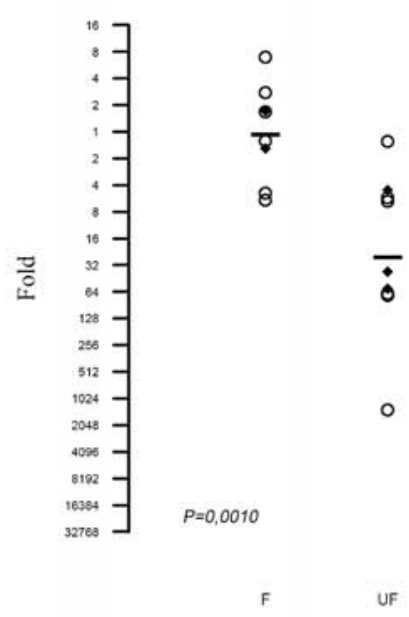

SLC6A2

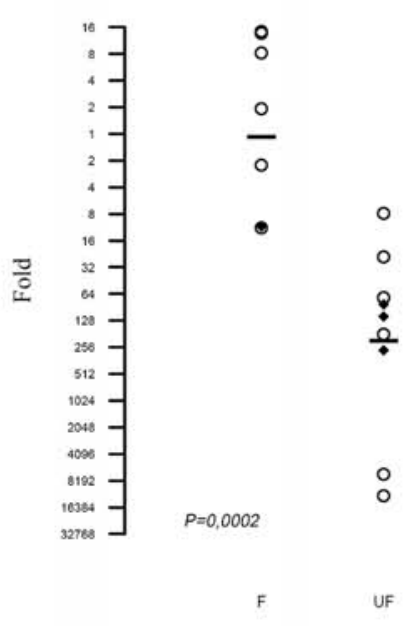

TH
PHOX2B

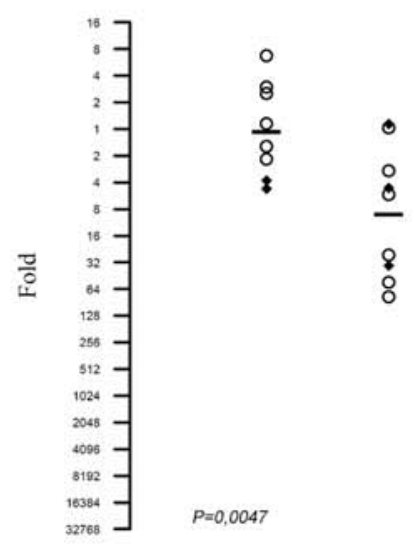

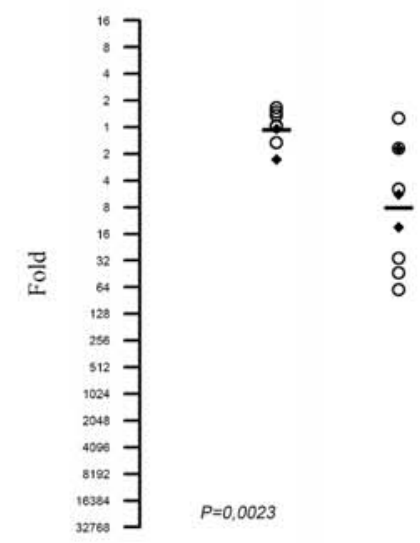

Figure 2. Scatter plots of the real-time PCR data from nine genes in the noradrenergic biosynthesis pathway. Expression values are presented as fold values from the mean of the favorable group (F). Expression values were normalized to the mean of three endogenous controls; ADA, GAPDH and GUSB. Filled square, cases used in the microarray analysis as well as in the real-time PCR study; open circle, cases used only in the real-time PCR analysis. Group: F, favourable tumor types; UF, unfavourable tumor types. P-values are calculated on the total data set (see Table II) by a two sample t-test on log 2 (i.e. Ct) expression values, assuming unequal variance. 


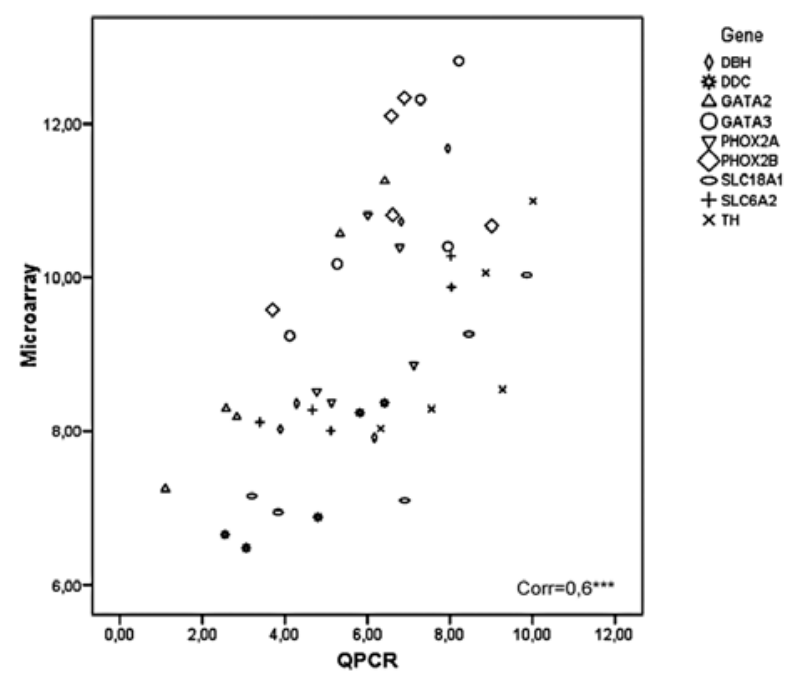

Figure 3. Correlation scatter plot between microarray and QPCR $\log _{2}$ expression values. Pearson's correlation $=0.6$.

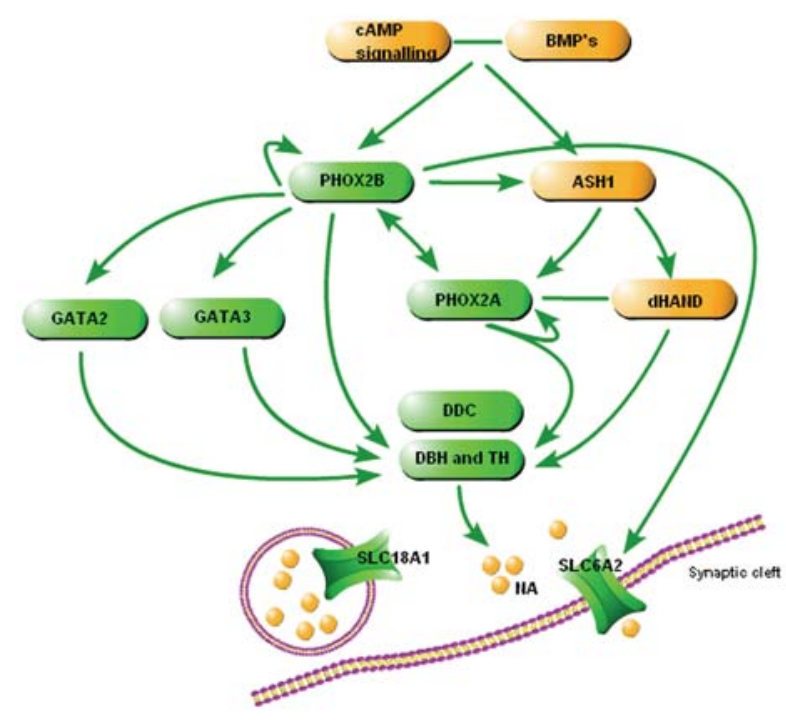

Figure 4. A simplified schematic representation of the noradrenalin biosynthesis pathway. Bone morphogenetic proteins (BMP's) induce expression of paired-like homeobox 2b (Phox2b) and ASCL1. cAMP signalling works synergistically with BMP's in promoting expression of these genes. ASCL1 and Phox $2 \mathrm{~b}$ are needed to induce expression of Phox $2 \mathrm{a}$. The two, highly conserved Phox2-proteins are involved in the expression of dopamine $B$ hydroxylase (DBH) and tyrosine hydroxylase $(\mathrm{TH})$, which together with dopamine decarboxylase (DDC) are involved in the final catalysis of dopamine to noradrenaline (NA). SLC6A2 participates in the reuptake of neurotransmitter from and to the synaptic cleft, and SLC18A1 participates in the transport of monoamines across the vesicle membranes. Genes marked in green showed significantly lower expression in unfavorable tumor types in the present study.

and a $62-98 \%$ coverage in the remaining $17 \%$. However, all important regulatory sites [two homeobox binding sites (hbs) and TATA-box, see Fig. 1] were covered in all samples in both directions. The sequencing of the $P H O X 2 A$ gene revealed only one silent base-pair substitution in exon 1 (156 C>T, Leu52Leu), which was found in two cases $(15 \mathrm{E} 6,25 \mathrm{~S} 8)$ and in the CEPH control.

\section{Discussion}

NB is one of the most frequent types of cancers among young children and the most common among infants. The tumor originates from an immature cell in the sympathetic ganglia, a branch of the autonomic peripheral nervous system characterized by the production of the neurotransmitter noradrenalin. Early actors in the noradrenalin biosynthesis pathway are bone morphogenetic proteins (BMPs), produced by the developing aorta (Fig. 4). One of the many important functions of these proteins is to induce expression of the basic Helix-loop-helix transcription factor achaete-scute complexlike 1 (ASCL1), which is essential for development of peripheral sympathetic and parasympathetic neurons $(23,24)$. BMPs also induce expression of Phox $2 b$, a homeobox transcription factor shown to be mutated in primary NB tumors (7-10). Although independently expressed, in sympathetic ganglia it seems like Phox $2 b$ is necessary for maintained expression of ASCL1 $(12,15)$. Recent findings suggest that cAMP signaling works synergistically with BMPs in promoting expression of these genes (25) (Fig. 4). ASCL1 and Phox $2 b$ are essential to induce expression of the Phox $2 b$ homologue Phox2a $(13,14)$. Both Phox $2 a$ and Phox2b are involved in the expression of dopamine $\beta$ hydroxylase (DBH), which catalyze the conversion of dopamine to noradrenalin and tyrosine hydroxylase $(\mathrm{TH})$, the rate-limiting enzyme in the biosynthesis of noradrenalin (26). The catecholeamine synthesis is also dependent on the dopa decarboxylase (DDC) enzyme that converts L-DOPA into dopamine. The genes encoding these three enzymes has previously been identified as the top-ranked classifiers in studies on NB (27-29). The function of the two Phox proteins differs in some aspects; while Phox $2 b$ is required for generation and maintenance of all noradrenergic cells $(11,12)$, Phox 2 a seems to be more necessary for the brain noradrenergic centers (locus corelueus), $(16,30)$. Overexpression of Phox $2 \mathrm{a}$ and Phox $2 \mathrm{~b}$ in vivo engenders additional noradrenergic neurons (31), while mice lacking $P H O X 2 B$ die before birth with abnormal and reduced chromaffin cells in the adrenal medulla (32). Other downstream targets of ASCL1 and Phox $2 \mathrm{~b}$, are the GATA binding protein 2/3 (GATA2 and GATA3) and dHAND, transcription factors involved in the noradrenergic pathway (12) (Fig. 4). Both GATA2 and GATA3 have previously been shown to discriminate between groups of NB tumors $(28,29)$. Phox $2 b$ probably also controls expression of solute carrier family 6 (neurotransmitter transporter, noradrenalin, member 2; SLC6A2), which participates in the re-uptake of neurotransmitter from the synaptic cleft (16). Another important catecholeamine transporter in noradrenaline-producing chromaffin cells or neurons is SLC18A1 (also called VMAT1; vesicular monoamine transporter 1 ). The differential expression levels of its transcript have been discussed in previous studies concerning neuroblastoma (33), phaeochromocytoma $(34,35)$, as well as in gastrointestinal endocrine tumors (36). In a recent study, Revet and colleagues showed a connection of the Phox2-pathway to the Delta-Notch pathway via the homeobox transcription factor MSX1 (37). They found the MSX1 transcript to be down-regulated after induction of Phox $2 b$ expression and thus the role of MSX1 seems to be repression of neural differentiation. However, in 
the current study we could not find any evidence for MSX1 up-regulation in unfavorable cases.

The evolutionary conserved Phox 2 proteins (Phox $2 \mathrm{a}$ and Phox $2 b$ ) are the upstream key mediators of the noradrenalin biosynthesis and mutations in genes encoding them have been linked to several different syndromes. $P H O X 2 B$ is a primary disease locus in congenital central hypoventilation syndrome (CCHS), a rare syndrome characterized by impaired autonomous breathing (38). Mutations in $P H O X 2 B$ have also been found in patients with a complex combination of neural crest abnormalities, as well as in Hirschsprung disease (HSCR) which is characterized by absence of enteric ganglia. Several patients with CCHS and HSCR also suffer from NB $(9,38,39)$. Moreover, both hereditary and sporadic cases of NB have been found to show mutations in the $P H O X 2 B$ gene, although at low frequencies $(7,8,10)$. Mutations in $P H O X 2 A$ have been found in patients with congenital fibrosis of the extraocular muscles (CFEOM), a disorder that might result from maldevelopment of these nerve nuclei. In a study made by Nakano and colleagues, two splice-site mutations and one missense mutation were found (21). The fact that PHOX2A was the 6th most significant gene from the microarray gene list, that it is localized within the region often deleted in chromosome 11q and that it is directly regulated by Phox $2 \mathrm{~b}$ encouraged us to screen the coding and promoter region of PHOX2A by DNA sequencing. As can be visualized in Fig. 1, the promoter region contains several regulatory sites, including the Phox $2 \mathrm{~b}$ binding site, where mutations might affect the induction of $P H O X 2 A$ expression (13). However, no alterations were found in the regulatory or coding parts of $P H O X 2 A$ in this study.

The current study is based upon a gene list of differentially expressed genes from a microarray expression study (Affymetrix HU133A). Out of the genes found to show lower expression in unfavorable NB tumors, nine noradrenalin biosynthesis pathway actors (Fig. 4) were among the most significant transcripts (Table II). These results could be significantly verified in a second set of tumors by real-time PCR with TaqMan (Fig. 2). The interpretation of the lower expression of this pathway in unfavorable tumors can be discussed. This result could simply reflect the differentiation state in which high-risk tumors are more immature, also suggested by others (29). In that case, the present findings suggest the Phox 2 pathway expression status to be an excellent marker for determination of the differentiation grade of $\mathrm{NB}$ tumors. On the other hand, the result could also reflect the importance of the deregulation of this pathway in tumor development. This suggestion is supported by the fact that $P H O X 2 B$ is mutated in hereditary and in a few sporadic NB cases (7-10). Thus, one could speculate that a mutation in the $P H O X 2 B$ gene is one of several ways to suppress this pathway in high-risk tumors.

In conclusion, a significant difference in expression of the noradrenalin biosynthesis pathway was found between highand low-risk NB tumor types. This finding has been indicated by earlier studies (27-29), but the current study is the first to verify these results by a more robust technique in a separate patient material. In the current study, we screened the $P H O X 2 \mathrm{~A}$ gene for mutations in primary sporadic NB tumors. However, no evidence for involvement in tumor development could be found. One could speculate that the presence of global epigenetic differences between favorable and unfavorable NB tumors might be responsible for modulating expression of this critical pathway and others. The study of such epigenetic patterns on a wide genome scale is presently ongoing at our laboratory.

\section{Acknowledgements}

We would like to thank the Swegene Microarray Resource Centre in Lund for running the microarray expression analysis. Also, thanks to Genomics Core Facility resource unit at the University of Gothenburg for help and access to the ABI PRISM $^{\circledR} 7900$ HT Sequence Detection System. This study was supported by grants from the Swedish Medical Council, the Children's Cancer Foundation, the King Gustav V Jubilee Clinic Cancer Research Foundation, the Assar Gabrielsson Foundation, the Wilhelm and Martina Lundgren Research Foundation and the Nilsson-Ehle Foundation. The study has been approved by the Ethics Committee at the Uppsala University.

\section{References}

1. Brodeur GM: Neuroblastoma: biological insights into a clinical enigma. Nat Rev Cancer 3: 203-216, 2003.

2. Brodeur GM, Sekhon G and Goldstein MN: Chromosomal aberrations in human neuroblastomas. Cancer 40: 2256-2263, 1977.

3. Spitz R, Hero B, Simon T and Berthold F: Loss in chromosome $11 \mathrm{q}$ identifies tumors with increased risk for metastatic relapses in localized and 4S neuroblastoma. Clin Cancer Res 12: 3368-3373, 2006

4. Guo C, White PS, Weiss MJ, et al: Allelic deletion at $11 \mathrm{q} 23$ is common in MYCN single copy neuroblastomas. Oncogene 18: 4948-4957, 1999

5. Maris JM, Guo C, White PS, et al: Allelic deletion at chromosome bands 11q14-23 is common in neuroblastoma. Med Pediatr Oncol 36: 24-27, 2001.

6. Mosse Y, Greshock J, King A, Khazi D, Weber BL and Maris JM: Identification and high-resolution mapping of a constitutional $11 \mathrm{q}$ deletion in an infant with multifocal neuroblastoma. Lancet Oncol 4: 769-771, 2003.

7. Krona C, Caren H, Sjoberg RM, et al: Analysis of neuroblastoma tumour progression; loss of $\mathrm{PHOX} 2 \mathrm{~B}$ on $4 \mathrm{p} 13$ and $17 \mathrm{q}$ gain are early events in neuroblastoma tumourigenesis. Int J Oncol 32: 575-583, 2008.

8. Mosse YP, Laudenslager M, Khazi D, et al: Germline PHOX2B mutation in hereditary neuroblastoma. Am J Hum Genet 75: 727-730, 2004

9. Trochet D, Bourdeaut F, Janoueix-Lerosey I, et al: Germline mutations of the paired-like homeobox 2B (PHOX2B) gene in neuroblastoma. Am J Hum Genet 74: 761-764, 2004.

10. van Limpt V, Schramm A, van Lakeman A, et al: The Phox2B homeobox gene is mutated in sporadic neuroblastomas. Oncogene 23: 9280-9288, 2004.

11. Huber K, Karch N, Ernsberger U, Goridis C and Unsicker K: The role of Phox2B in chromaffin cell development. Dev Biol 279: 501-508, 2005.

12. Pattyn A, Goridis C and Brunet JF: Specification of the central noradrenergic phenotype by the homeobox gene Phox $2 \mathrm{~b}$. Mol Cell Neurosci 15: 235-243, 2000.

13. Flora A, Lucchetti H, Benfante R, Goridis C, Clementi F and Fornasari D: Sp proteins and Phox $2 b$ regulate the expression of the human Phox2a gene. J Neurosci 21: 7037-7045, 2001.

14. Lo L, Tiveron MC and Anderson DJ: MASH1 activates expression of the paired homeodomain transcription factor Phox $2 \mathrm{a}$, and couples pan-neuronal and subtype-specific components of autonomic neuronal identity. Development 125 : 609-620, 1998.

15. Brunet JF and Pattyn A: Phox2 genes - from patterning to connectivity. Curr Opin Genet Dev 12: 435-440, 2002. 
16. Rychlik JL, Hsieh M, Eiden LE and Lewis EJ: Phox2 and dHAND transcription factors select shared and unique target genes in the noradrenergic cell type. J Mol Neurosci 27: 281-292, 2005.

17. Brodeur GM, Pritchard J, Berthold F, et al: Revisions of the international criteria for neuroblastoma diagnosis, staging, and response to treatment. J Clin Oncol 11: 1466-1477, 1993.

18. Martinsson T, Sjoberg RM, Hallstensson K, Nordling M, Hedborg $\mathrm{F}$ and Kogner P: Delimitation of a critical tumour suppressor region at distal 1p in neuroblastoma tumours. Eur J Cancer 33: 1997-2001, 1997.

19. Martinsson T, Sjoberg RM, Hedborg F and Kogner P: Deletion of chromosome $1 \mathrm{p}$ loci and microsatellite instability in neuroblastomas analyzed with short-tandem repeat polymorphisms. Cancer Res 55: 5681-5686, 1995.

20. Carén H, Erichsen J, Olsson L, et al: High-resolution array copy number analyses and MLPA for detection of deletion, gain, amplification and copy-neutral LOH in primary neuroblastoma tumors; Four cases of homozygous deletions of the CDKN2A gene. BMC Genomics 9: 353, 2008.

21. Nakano M, Yamada K, Fain J, et al: Homozygous mutations in ARIX(PHOX2A) result in congenital fibrosis of the extraocular muscles type 2. Nat Genet 29: 315-320, 2001.

22. Vandesompele J, De Preter K, Pattyn F, et al: Accurate normalization of real-time quantitative RT-PCR data by geometric averaging of multiple internal control genes. Genome Biol 3: Research0034, 2002.

23. Guillemot F and Joyner AL: Dynamic expression of the murine Achaete-Scute homologue Mash-1 in the developing nervous system. Mech Dev 42: 171-185, 1993.

24. Hirsch MR, Tiveron MC, Guillemot F, Brunet JF and Goridis C: Control of noradrenergic differentiation and Phox2a expression by MASH1 in the central and peripheral nervous system. Development 125: 599-608, 1998.

25. Chen S, Ji M, Paris M, Hullinger RL and Andrisani OM: The cAMP pathway regulates both transcription and activity of the paired homeobox transcription factor Phox 2 a required for development of neural crest-derived and central nervous system-derived catecholaminergic neurons. J Biol Chem 280: 41025-41036, 2005

26. Anderson DJ, Carnahan JF, Michelsohn A and Patterson PH: Antibody markers identify a common progenitor to sympathetic neurons and chromaffin cells in vivo and reveal the timing of commitment to neuronal differentiation in the sympathoadrenal lineage. J Neurosci 11: 3507-3519, 1991.

27. Oberthuer A, Warnat P, Kahlert Y, et al: Classification of neuroblastoma patients by published gene-expression markers reveals a low sensitivity for unfavorable courses of MYCN non-amplified disease. Cancer Lett 250: 250-267, 2007.
28. Ohira M, Oba S, Nakamura Y, et al: Expression profiling using a tumor-specific cDNA microarray predicts the prognosis of intermediate risk neuroblastomas. Cancer Cell 7: 337-350, 2005.

29. Wang Q, Diskin S, Rappaport E, et al: Integrative genomics identifies distinct molecular classes of neuroblastoma and shows that multiple genes are targeted by regional alterations in DNA copy number. Cancer Res 66: 6050-6062, 2006.

30. Morin X, Cremer H, Hirsch MR, Kapur RP, Goridis C and Brunet JF: Defects in sensory and autonomic ganglia and absence of locus coeruleus in mice deficient for the homeobox gene Phox2a. Neuron 18: 411-423, 1997.

31. Stanke M, Junghans D, Geissen M, Goridis C, Ernsberger U and Rohrer H: The Phox2 homeodomain proteins are sufficient to promote the development of sympathetic neurons. Development 126: 4087-4094, 1999.

32. Pattyn A, Morin X, Cremer H, Goridis C and Brunet JF: The homeobox gene Phox $2 \mathrm{~b}$ is essential for the development of autonomic neural crest derivatives. Nature 399: 366-370, 1999.

33. De Preter K, Vandesompele J, Heimann P, et al: Human fetal neuroblast and neuroblastoma transcriptome analysis confirms neuroblast origin and highlights neuroblastoma candidate genes. Genome Biol 7: R84, 2006.

34. Huynh TT, Pacak K, Brouwers FM, et al: Different expression of catecholamine transporters in phaeochromocytomas from patients with von Hippel-Lindau syndrome and multiple endocrine neoplasia type 2. Eur J Endocrinol 153: 551-563, 2005.

35. Kolby L, Bernhardt P, Johanson V, et al: Can quantification of VMAT and SSTR expression be helpful for planning radionuclide therapy of malignant pheochromocytomas? Ann NY Acad Sci 1073: 491-497, 2006

36. Jakobsen AM, Andersson P, Saglik G, et al: Differential expression of vesicular monoamine transporter (VMAT) 1 and 2 in gastrointestinal endocrine tumours. J Pathol 195: 463-472, 2001.

37. Revet I, Huizenga G, Chan A, et al: The MSX1 homeobox transcription factor is a downstream target of PHOX2B and activates the Delta-Notch pathway in neuroblastoma. Exp Cell Res 314: 707-719, 2008

38. Amiel J, Laudier B, Attie-Bitach T, et al: Polyalanine expansion and frameshift mutations of the paired-like homeobox gene PHOX2B in congenital central hypoventilation syndrome. Nat Genet 33: 459-461, 2003.

39. Weese-Mayer DE, Berry-Kravis EM, Zhou L, et al: Idiopathic congenital central hypoventilation syndrome: analysis of genes pertinent to early autonomic nervous system embryologic development and identification of mutations in PHOX2b. Am J Med Genet A 123: 267-278, 2003. 